\title{
Malignant transformation in a patient with fibrous dysplasia and aneurysmal bone cyst
}

\author{
Thomas Tværmose Troelsen*1,2 ${ }^{2}$, Peter Holmberg Jørgensen ${ }^{1}$, Steen Bærentzen ${ }^{3}$, Thomas Baad-Hansen ${ }^{1}$ \\ ${ }^{1}$ Department of Orthopedics, Aarhus University Hospital NBG, Aarhus, Denmark \\ ${ }^{2}$ Department of Anesthesia, Regional Hospital of Randers, Randers, Denmark \\ ${ }^{3}$ Department of Pathology, Aarhus University Hospital NBG, Aarhus, Denmark
}

Received: December 3, 2015

DOI: $10.5430 /$ jst.v6n2p30
Accepted: April 28, $2016 \quad$ Online Published: May 11, 2016

URL: http://dx.doi.org/10.5430/jst.v6n2p30

\begin{abstract}
A 38-year old-woman, with a history of monostotic fibrous dysplasia (MFD) of the right femur-developed secondary transformation to both an osteosarcoma and an aneurysmal bone cyst. The patient was initially treated with wide resection and insertion of a hip prosthesis and postoperative chemotherapy. After three months she had a recurrence and a hemipelvectomy was performed, followed by chemotherapy. Seven years later the patient is still alive with no signs of metastases. It is unknown whether the osteosarcoma developed from the MFD or from the aneurysmal bone cyst.
\end{abstract}

Secondary transformation of fibrous dysplasia into osteosarcoma is rare, especially in MFD without concomitant McCuneAlbright syndrome as well as in patients with MFD without prior radiation therapy. Transformation of an aneurysmal bone cyst is an even more rare event.

This case is reported due to the rare event of malignant transformation of MFD with a concomitant aneurysmal bone cyst and due to the favorable outcome, despite the poor prognosis.

Key Words: Fibrous dysplasia, Monostotic, Bone cysts, Aneurysmal, Osteosarcoma, Cell transformation, Neoplastic

\section{INTRODUCTION}

Lichtenstein first used the term Fibrous Dysplasia (FD) in 1938, describing a filling of the medullary cavity by a "gritty, grayish white fibrous tissue containing trabeculae of newly formed primitive bone". ${ }^{[1]}$ FD can be present in both a monoostotic and a polyostotic form. ${ }^{[2]}$ The polyostotic FD can be linked to endocrine and pigmentation abnormalities known as McCune-Albright syndrome..$^{[3,4]}$

Malignant transformation of FD is rare. It was first described in $1945^{[5]}$ and subsequently in a number of case reports. In a retrospective study from 1994, Ruggieri et al. described an incidence of malignant transformation in 28 out of 1,122 cases with FD. ${ }^{[6]}$ The reported malignancies were predominantly osteosarcoma followed by chondrosarcoma, fibrosarcoma and malignant fibrous histiocytoma. The primary site of transformation was the maxillofacial bones, followed by the proximal femur.

Aneurysmal bone cyst (ABC) first described in $1942,{ }^{[7]}$ is a benign lesion often arising secondary to other bone lesions. In a review of 639 bone lesions $A B C$ was reported in 123 cases of which 87 were primary $\mathrm{ABC}$ and 36 secondary to other lesions. Of the secondary $\mathrm{ABCs}$ only one arose from FD. ${ }^{[8]}$ Malignant transformation of an ABC to osteosarcoma has been reported previously in the literature. ${ }^{[9-13]}$

\footnotetext{
*Correspondence: Thomas Tværmose Troelsen; Email: Troelsentt@gmail.com; Address: Department of Orthopedics, Aarhus University Hospital NBG, 8000 Aarhus, Denmark.
} 
In the present case, both an osteosarcoma and an aneurysmal bone cyst were present in the proximal femur of a patient with known monostotic fibrous dysplasia (MFD).

\section{CASE}

The current case is a 38-year-old woman with known a history of FD of the right proximal femur. The patient was first diagnosed with FD and operated abroad with curettage and bone grafting in 1976. The patient was referred to our department in 1992 after she immigrated to Denmark. At our department she was treated once more with curettage and bone grafting. The tissue retrieved in 1992 revealed FD with no other pathology (see Figure 1A). No further follow-up was planned.

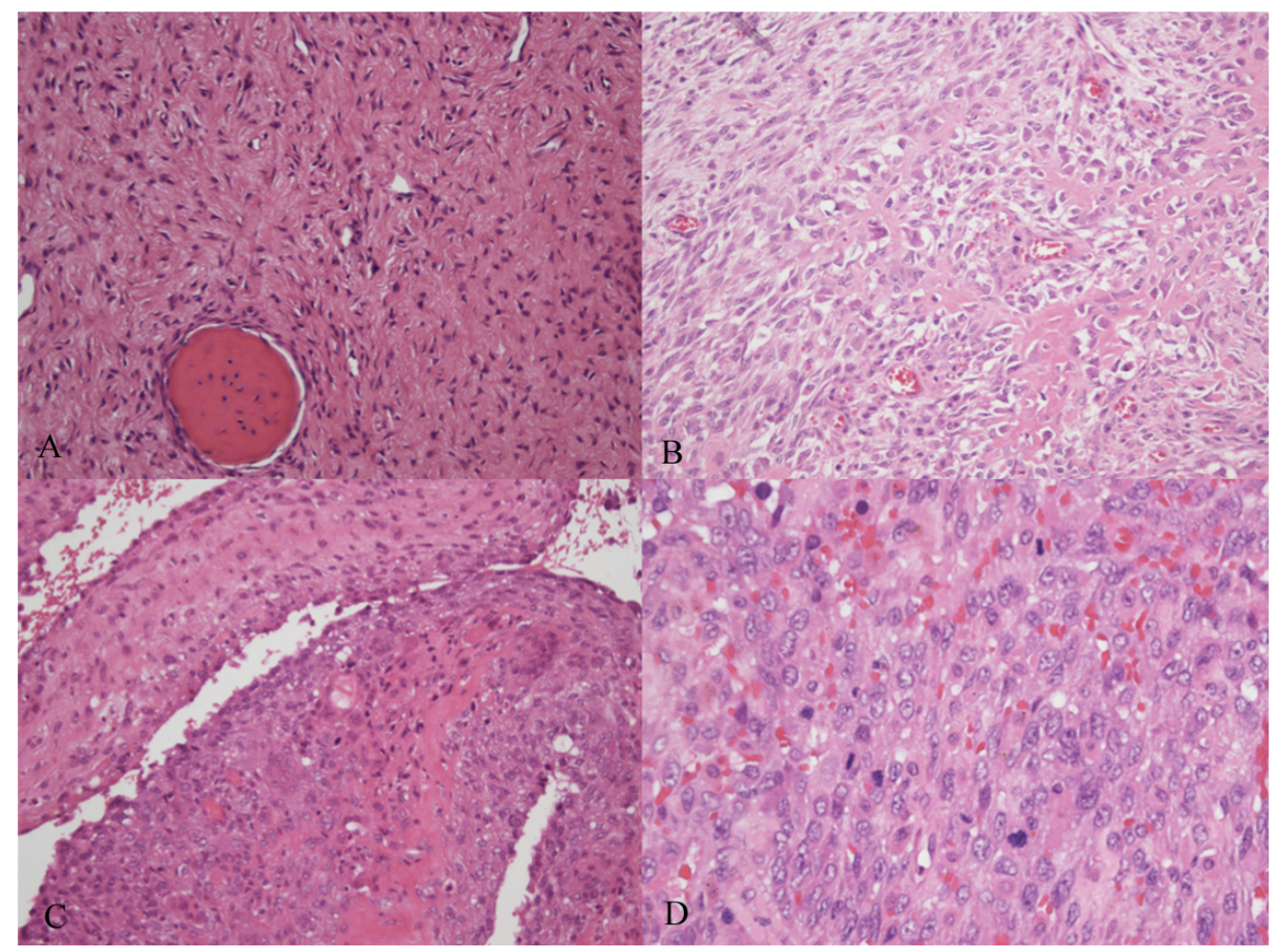

Figure 1. A. Fibrous dysplasia 1992, H\&E x 200. B. Osteoblastic osteosarcoma 2009, H\&E x 200. C. Aneurismal bone cyst 2009, H\&E x 200. D. Solid osteosarcoma 2009, H\&E x 400.

In 2001, she was readmitted to our department due to a slight pain in the hip region. Radiographs showed hip arthrosis and signs of FD (see Figure 2A), almost unchanged compared to previous radiographs from 1992 (radiographs from 1992 are no longer available). The FD was moderate and no surgery was performed.

In 2009, the patient had a minor trauma to the right hip. Radiographs on admission showed multiple, inhomogeneous, cystic changes in the trochanteric region and arthrosis of the hip joint (see Figure 2C). An open biopsy revealed an aneurysmal bone cyst (see Figure 1C) containing small areas of FD. Some areas were suspicious for malignancy due to a high frequency of mitosis; however, these changes were interpreted as reactive changes due to the trauma. The hip movement was decreased (flexion 0-90 ${ }^{\circ}$, ab-/adduction $40 / 5^{\circ}$, internal rotation $15^{\circ}$, external rotation $0^{\circ}$ ) and the pain was mainly present during activity consistent with arthrosis. Two months later the patient was evaluated with a view to hip replacement surgery; new radiograph (see Figure 2B) showed slight progression of the cystic changes. Curettage of the cystic areas was planned along with insertion of a hip replacement prosthesis. Surgery was scheduled six weeks later. When admitted prior to surgery the patient presented with worsening of the hip pain and a new radiograph unexpectedly demonstrated a pertrochanteric fracture with massive osteolytic changes, at this time still attributed to FD with ABC (see Figure 2D). Surgery revealed a large soft-tissue tumour, suspected for malignancy and consequently a primary prosthesis was never inserted. In stead all tissue with malignant appearance was excised in macroscopically healthy tissue. Histopathology showed areas with widespread primitive osteoid formation, positive alkaline phosphatase staining, nuclear atypia and pleomorphism, mitotic activity of 15-20 
mitoses per 10 high power fields and necrosis, which was now interpreted as osteosarcoma (see Figure 1, B\&D). Areas resembling FD and aneurysmal bone cyst were still present.
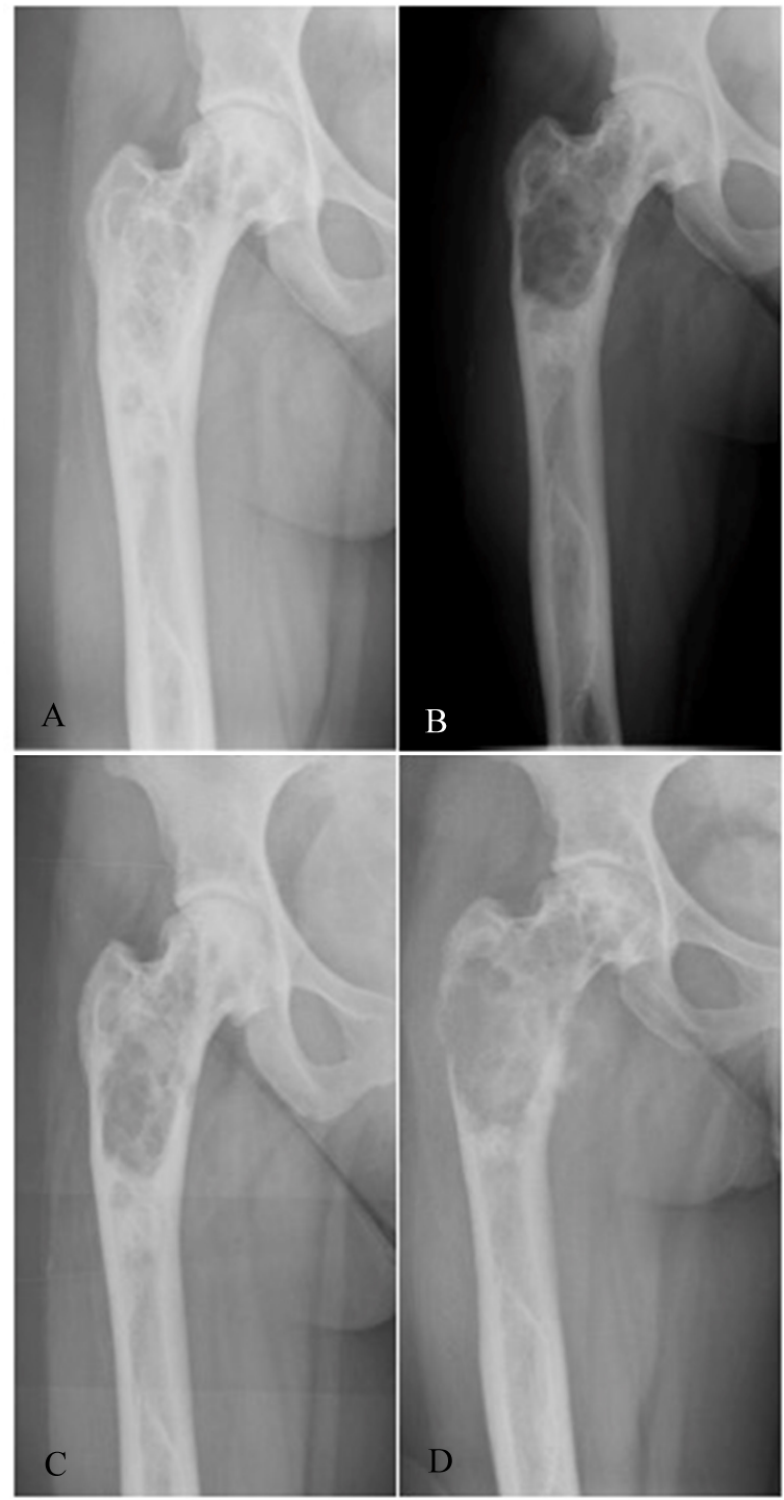

Figure 2. A) Radiograph of the right hip January 2001 showing FD with a ground glass appearance and sequelae from previous surgery without major cystic lesions; B)

Radiograph of the right hip from March 2009 showing slight progression of the cystic lesions; C) Radiograph of the right hip from January 2009 showing FD with a new cystic lesion and hip arthrosis; D) Radiograph showing increased osteolysis, with irregular cortical bone and fracture.

A CT-scan revealed no signs of skip lesions or distant metastases and a wide resection (amputation) of the affected area was performed. Postoperatively the patient received chemotherapeutic treatment with Doxorubicin $37.5 \mathrm{mg} / \mathrm{m}^{2}$ and Cisplatin $60 \mathrm{mg} / \mathrm{m}^{2}$ on days $1 \& 2$, in weeks $1-4$ and
Methotrexate $12 \mathrm{~g} / \mathrm{m}^{2}$ in weeks 5-6. Two series were given.

Three months after the amputation the patient experienced a periacetabular recurrence with heavy involvement of the soft tissue. A hemipelvectomy was now performed combined with postoperative chemotherapy consisting of Ifosfamide $3 \mathrm{~g} / \mathrm{m}^{2}$ and Etoposide $120 \mathrm{mg} / \mathrm{m}^{2}$ three days a week. She received 6 series; series 2-6 were reduced in dose to $75 \%$ due to an Ifosfamide-induced transient encephalopathy episode after the first series. At present, the patient has been followed up regularly for seven years with no further signs of local or disseminated disease.

The patient showed no signs of McCune-Albright syndrome such as café au lait spots or any endocrine disturbances ${ }^{[14]}$ but the diagnosis was not excluded by genetic testing.

\section{Discussion}

This case demonstrates a long history of MFD in which a secondary $\mathrm{ABC}$ and an osteosarcoma developed 17 years after the initial treatment with a very rapid destruction of the bone leading to a fracture within a few months. Both entities have been described to develop in FD, no reports of all three pathologies existing concomitantly have been found. Secondary osteosarcoma developing from fibrous dysplasia is estimated to occur in $2.5 \%$ of all cases ${ }^{[6]}$ and the rates reported in the literature may even overestimate the incidence as asymptomatic cases of MFD are not evaluated. Development of malignancy is most often seen in polyosteotic forms combined with endocrine abnormalities, known as McCune-Albright syndrome, and after radiation therapy. ${ }^{[6]}$ Malignant transformation seems most likely to occur after the third decade of life. ${ }^{[6]} \mathrm{ABC}$ has previously been described to occur in $\mathrm{FD},{ }^{[8,15,16]}$ often as a secondary lesion, as reported in the present case. Malignant transformation of $\mathrm{ABC}$ has been described previously although even more rare than from FD. ${ }^{[9,11,12,17]}$ In the present case it remains unknown, whether this was the case or whether malignancy arose secondary to the fibrous dysplasia or both. ABC can be seen in primary and secondary forms with expression of the USP6 gene in the primary forms; this is not seen in the secondary ones as in FD. ${ }^{[18]} \mathrm{ABC}$ might histologically resemble teleangiectatic osteosarcoma and they cannot be distinguished by investigation for the USP6 gene. ${ }^{[18]}$ However, cellular atypia is usually not seen in the membranes of $\mathrm{ABC}$, although the transition between the two histological entities is not always clear. ${ }^{[12,19-21]}$

Osteosarcoma is clinically indicated by pain and mass growth with osteolytic changes on radiographs.

Our patient was known with recurrence of cystic changes as can be seen in FD. Previous biopsies revealed FD and 
secondary aneurysmal bone cyst, and the patient had clinical signs of arthrosis confirmed by radiographs. Thus, an MRI scan was not performed prior to the patient's hip surgery (this was only done at admission in 2001), although this probably could have demonstrated early signs of malignancy.

The diagnosis of osteosarcoma was made perioperatively and confirmed by histopathology (see Figure 1, B\&D).

The standard treatment of osteosarcoma is pre-operative chemotherapy, followed by surgery and post-operative chemotherapy. This treatment has improved the 5-year survival to $70 \%-80 \%$ compared to less than $20 \%$ with surgery alone in localized disease. Relapse of disease is associated with a 5 year survival of $10 \%-30 \% .^{[22]}$

Due to the patients fracture, we chose not to treat the patient with preoperative chemotherapy; thus the patient was treated with a wide resection (amputation) combined with adjuvant chemotherapy alone.

In our opinion this case does not suggest the need of regular follow-up of patients with FD as the malignancy is rare and can occur many years after appearance of the primary FD lesion. However, awareness of the possibility of malignant transformation is important when evaluating patients with a history of FD and maybe even more in patients with a history of multiple bone abnormalities.

\section{Conclusion}

Monostotic fibrous dysplasia and aneurysmal bone cysts very rarely turn into a secondary benign or malignant condition, though both can be seen. Even if there could be other reasons for the pain (e.g. arthrosis) the possibility of malignant transformation should be kept in mind. Due to the rarity and late malignant transformation we would not recommend following all cases of FD or ABC closely. However, a change in symptomatology, especially worsening of pain, should lead to increased awareness of malignant dedifferentiation.

The main clinical feature in previous cases, as well as in our case, was pain increasing over a shorter period of time.

\section{CONFLicts OF InTEREST Disclosure}

The authors declare that there is no conflict of interest statement.

\section{REFERENCES}

[1] Lichtenstein L. POlyostotic fibrous dysplasia. Arch Surg. 1938; 36(5): 874-98. http://dx.doi.org/10.1001/archsurg. 1938 .01190230153012

[2] Jaffe HL, Lichtenstein L. Non-osteogenic fibroma of bone. Am J Pathol. 1942; 18(2): 205-21. PMid:19970624.

[3] Albright F, Butler AM, Hampton AO, et al. Syndrome Characterized by Osteitis Fibrosa Disseminata, Areas of Pigmentation and Endocrine Dysfunction, with Precocious Puberty in Females. N Engl J Med. 1937; 216(17): 727-46. http://dx.doi .org/10.1056/N EJM193704292161701

[4] Mc CD, Bruch H. Osteodystrophia fibrosa: Report of a case in which the condition was combined with precocious puberty, pathologic pigmentation of the skin and hyperthyroidism, with a review of the literature. Am J Dis Child. 1937; 54(4): 806-48. http: //dx.doi.org/10.1001/archpedi.1937.01980040110009

[5] Coley BL, Stewart FW. Bone Sarcoma in Polyostotic Fibrous Dysplasia. Ann Surg. 1945; 121(6): 872-81. http://dx.doi.org/10. 1097/00000658-194506000-00012

[6] Ruggieri P, Sim FH, Bond JR, et al. Malignancies in fibrous dysplasia. Cancer. 1994; 73(5): 1411-24. http://dx.doi.org/10.1002/1097-0142(19940301)73: 5<1411: : AID-CNCR2820730516>3.0.C0;2-T

[7] Jaffe HL, Lichtenstein L. Solitary unicameral bone cyst: With emphasis on the roentgen picture, the pathologic appearance and the pathogenesis. Arch Surg. 1942; 44(6): 1004-25. http://dx.doi.o rg/10.1001/archsurg. 1942.01210240043003

[8] Martinez V, Sissons HA. Aneurysmal bone cyst. A review of 123 cases including primary lesions and those secondary to other bone pathology. Cancer. 1988; 61(11): 2291304. http://dx.doi.org/10.1002/1097-0142(19880601)6 $1: 11<2291:$ : AID-CNCR2820611125>3.0.CD;2-V

Published by Sciedu Press
[9] Brindley GW, Greene JF, Frankel LS. Case reports: malignant transformation of aneurysmal bone cysts. Clin Orthop Relat Res. 2005; 438: 282-7. PMid:16131903. http://dx.doi.org/10.1097/01. blo.0000176553.27976.b3

[10] Anract P, De PG, Jeanrot C, et al. Malignant fibrous histiocytoma at the site of a previously treated aneurysmal bone cyst: A case report. J Bone Joint Surg Am. 2002; 84-A(1): 106-11.

[11] Hsu CC, Wang JW, Huang $\mathrm{CH}$, et al. Osteosarcoma at the site of a previously treated aneurysmal bone cyst. A case report. J Bone Joint Surg Am. 2005; 87(2): 395-8. PMid:15687165. http: $/ / \mathrm{dx}$.doi.org/10.2106/JBJS.C.01625

[12] Kyriakos M, Hardy D. Malignant transformation of aneurysmal bone cyst, with an analysis of the literature. Cancer. 1991; 68(8): 177080. http://dx.doi.org/10.1002/1097-0142(19911015)68: 8<1770: : AID-CNCR2820680821>3.0.CD; $2-7$

[13] Wuisman P, Roessner A, Blasius S, et al. High malignant surface osteosarcoma arising at the site of a previously treated aneurysmal bone cyst. J Cancer Res Clin Oncol. 1993; 119(7): 375-8. PMid:8491756. http://dx.doi.org/10.1007/BF01218416

[14] Chapurlat RD, Orcel P. Fibrous dysplasia of bone and McCuneAlbright syndrome. Best practice \& research Clinical rheumatology. 2008; 22(1): 55-69. PMid:18328981. http://dx.doi.org/10.10 $16 / j$. berh .2007 .11 .004

[15] DiCaprio MR, Enneking WF. Fibrous dysplasia. Pathophysiology, evaluation, and treatment. J Bone Joint Surg Am. 2005; 87(8): 184864. PMid:16085630. http://dx.doi.org/10.2106/JBJS.D.02 942

[16] Arden RL, Bahu SJ, Lucas DR. Mandibular aneurysmal bone cyst associated with fibrous dysplasia. Otolaryngol Head Neck Surg. 1997; 117(6): S153-6. http://dx.doi.org/10.1016/S0194-5 998(97) $70087-1$ 
[17] Mei J, Gao YS, Wang SQ, et al. Malignant transformation of aneurysmal bone cysts: A case report. Chin Med J (Engl). 2009; 122(1): 110-2.

[18] Oliveira AM, Perez-Atayde AR, Inwards CY, et al. USP6 and CDH11 oncogenes identify the neoplastic cell in primary aneurysmal bone cysts and are absent in so-called secondary aneurysmal bone cysts. Am J Pathol. 2004; 165(5): 1773-80. http://dx.doi .org/10.10 16/S0002-9440(10)63432-3

[19] Janevska V, Spasevska L, Samardziski M, et al. From aneurysmal bone cyst to telangiectatic osteosarcoma with metastasis in inguinal lymph nodes - Case report. Med Pregl. 2015; 68(3-4): 127-32. PMid:26214993. http://dx.doi.org/10.2298/MPNS1504127 J
[20] Do TD, Renker EK, Weber MA. Simulation of teleangiectactic osteosarcoma by aneurysmatic bone cyst. Orthopade. 2013; 42(12): 1067-70. PMid:24337363. http://dx.doi.org/10.1007/s0013 2-013-2199-5

[21] Lee HM, Cho KS, Choi KU, et al. Aggressive aneurysmal bone cyst of the maxilla confused with telangiectatic osteosarcoma. Auris Nasus Larynx. 2012; 39(3): 337-40. PMid:21862268. http: //dx.doi.org/10.1016/j.anl.2011.05.002

[22] Luetke A, Meyers PA, Lewis I, et al. Osteosarcoma treatment - where do we stand? A state of the art review. Cancer Treat Rev. 2014; 40(4): 523-32. PMid:24345772. http://dx.doi.org/10.1016/j.ctr v.2013.11.006 